\title{
Early Stage Prurigo Pigmentosa : A Case Report
}

\author{
Emel ONAYGIL' ${ }^{\text {, Abdullah SONGUR }}{ }^{2}$, Zekayi KUTLUBAY ${ }^{3}$, Cuyan DEMIRKESEN ${ }^{1}$
}

'Department of Pathology, İstanbul University, Cerrahpaşa Faculty of Medicine, ISTANBUL, TURKEY,

Department of Dermatology ${ }^{2}$ Şanlıurfa Balıklıgol Hospital, ŞANLIURFA, TURKEY, ${ }^{3}$ sstanbul University, Cerrahpaşa Faculty of Medicine, iSTANBUL, TURKEY

\section{ABSTRACT}

Prurigo pigmentosa is a rare inflammatory dermatosis that primarily affects adolescents and young adults. Even though it is most commonly seen in Japanese women, other countries have reported cases with increasing frequency. It is characterized by erythematous papules and macules on the trunk, neck and chest that resolve leaving a reticulate hyperpigmentation. Some endogenous factors related with ketosis like fasting, diet, diabetes, pregnancy and exogenous agents like chrome, nickel, para-amino compounds have been accused of playing a role in etiology. Here we would like to present a case of a 16-year-old female patient who was referred to our clinic with pruritic lesions on the trunk and neck, consistent with the initial phase of prurigo pigmentosa, after a period of strict diet. Prurigo pigmentosa is a disease with distinctive histologic and clinical features. Due to its rare occurrence, an accurate diagnosis may be particularly challenging. Clinicopathological correlation is therefore crucial in the diagnosis of the disease in its early phase.

Key Words: Prurigo Pigmentosa, Diet, Histopathology

\section{INTRODUCTION}

Prurigo pigmentosa is a rare dermatosis characterized by localized, recurrent, erythematous papular and macular lesions on the back, neck, and chest that resolve to leave hyperpigmentation. Although the etiology of the disease is not well known, it primarily affects adolescents and young adults in the spring and summer seasons (1). We would like to present a case of a 16-year-old female patient who was referred to our clinic with pruritic lesions on the trunk and neck, consistent with the initial phase of prurigo pigmentosa, after a period of strict diet.

\section{CASE REPORT}

A 16-year-old female was referred to the dermatology department of our hospital with a one-month history of pruritic rashes on her trunk and neck. Her complaints had started as red, pruritic vesicles that paled and regressed within a week but recurrence of the pruritic vesicles was observed. It was reported that one month before the eruption of the lesions, the patient undertook a strict diet, and lost twenty kilograms within three months. There was no drug history related to the lesions but the patient was diagnosed with asthma two weeks after the eruption of the lesions, and she started being treated for asthma. Dermatological examination revealed excoriated erythematous papules on the neck, back, clavicular and intermammarian areas, as

(Turk Patoloji Derg 2018, 34:182-185)

Received : 07.04.2015 Accepted : 23.06.2015 well as pale brown reticular hyperpigmentation on the front chest with increasing prominence at the intermammarian area (Figure 1). Laboratory work was normal for complete blood count, erythrocyte sedimentation rate, biochemistry test, and complete urinalysis.

The histopathological examination of a punch biopsy from the back of the patient revealed neutrophils in the epidermis that were mostly widely spread, or grouped into clusters. There was irregular acanthosis, dyskeratotic cells, spongiosis, neutrophilic and eosinophilic spongiosis in the epidermis. The upper dermis revealed perivascular and interstitial infiltration of neutrophils, intermingled with lymphocytes, histiosytes, and a small number of eosinophils. Vascular proliferation, and neutrophils within the lumina of some vessels were evident (Figure 2,3). When the clinical findings, the history of the patient, and the histopathological features were evaluated together, it was concluded that the symptoms were consistent with the early stage of prurigo pigmentosa. After the patient was diagnosed as prurigo pigmentosa through clinical and histopathological evaluations, she was treated with 100 $\mathrm{mg} /$ day doxycycline. Ten days later, the patient reported complete relief from itchiness, and it was observed that the existing papules resolved to leave brown hyperpigmentation (Figure 4). It was decided to continue the treatment with doxycycline for two months.

Correspondence: Emel ONAYGIL

İstanbul Üniversitesi, Cerrahpaşa Tip Fakültesi, Patoloji Anabilim Dalı, İSTANBUL, TURKEY

E-mail: emel_dm@hotmail.com Phone: +90 2124142033 


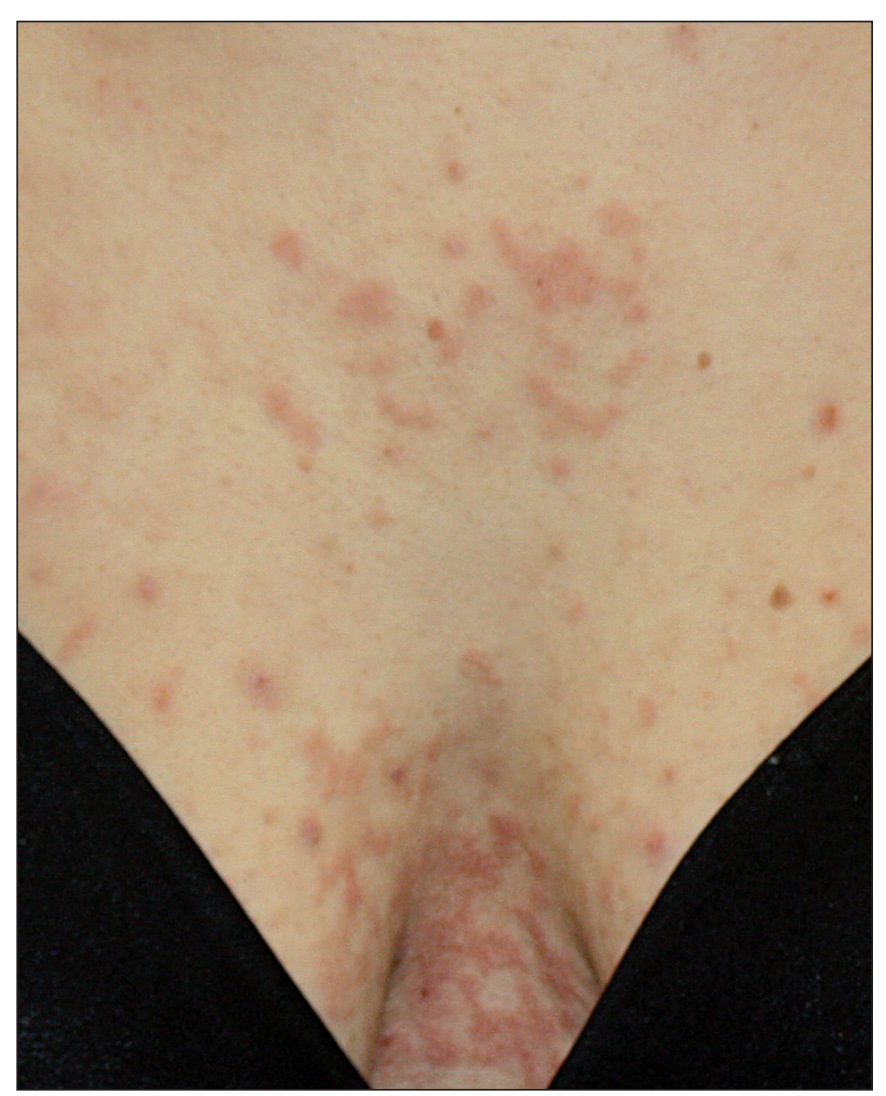

Figure 1: Edematous, papules and plaques, some of which are excoriated, coalescing on the neck laterals, intermammarian area, and anterior chest.

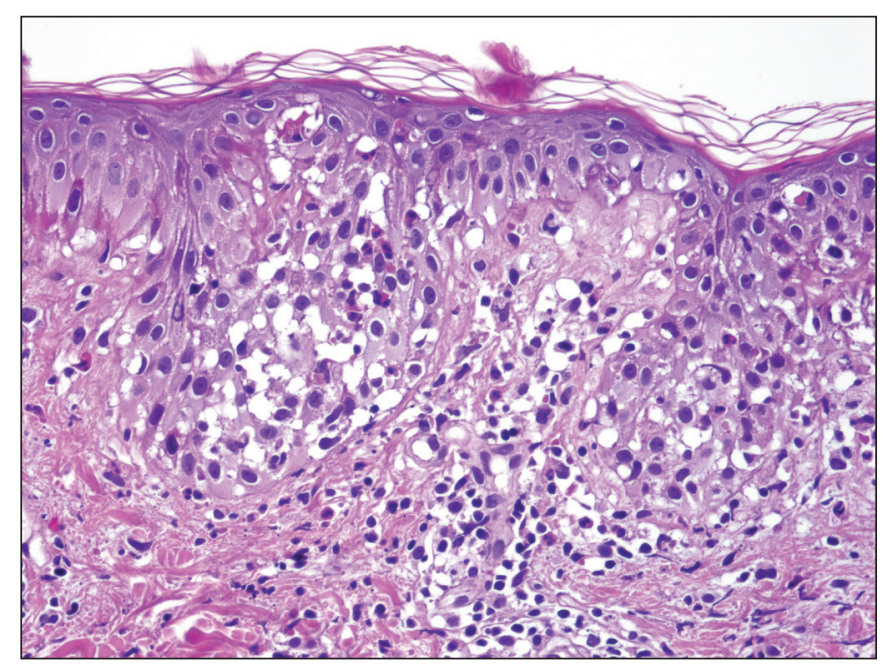

Figure 3: Neutrophils and dyskeratotic cells widely spread or grouped in clusters within the epidermis (H\&E; x100).

\section{DISCUSSION}

Prurigo pigmentosa was first described in 1971 by Nagashima et al. through observing the signs in 8 patients (1). In the following years, the Japanese literature

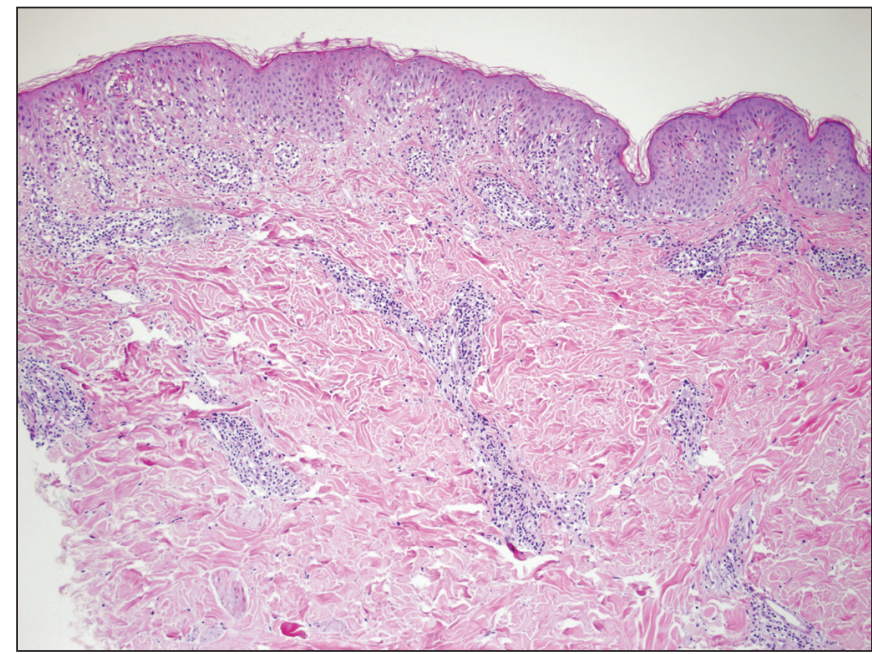

Figure 2: Perivascular and interstitial infiltration composed of neutrophils, lymphocytes, and histiocytes, vascular proliferation in the upper dermis (H\&E; $\mathrm{x} 40)$.

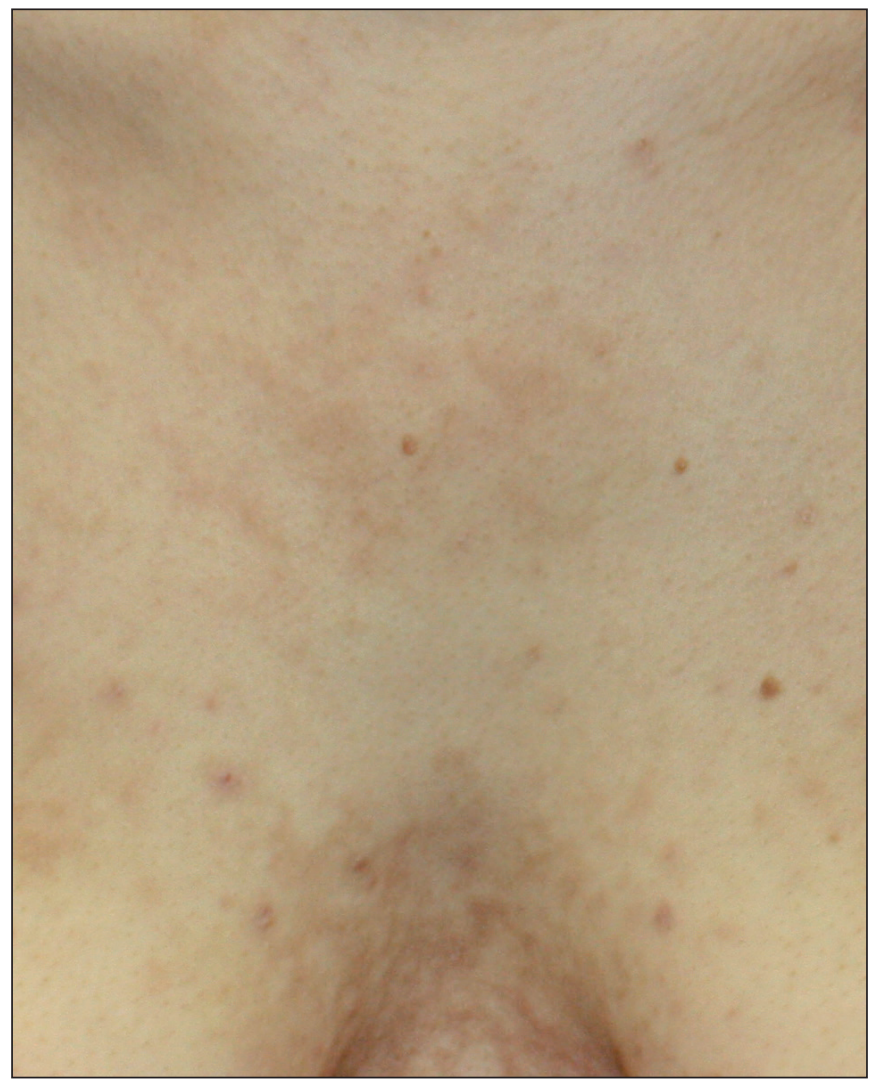

Figure 4: On the $10^{\text {th }}$ day of Doxycycline $100 \mathrm{mg} / \mathrm{g}$ treatment, papules and plaques resolved to leave light hyperpigmentation.

documented 300 cases of prurigo pigmentosa (2). While it is rarely seen outside Japan, cases have been reported in other countries with increasing frequency $(3,4)$. Baykal et al. published a series of case studies of 6 patients in 2006 
demonstrating that the disease is not as uncommon in Turkey as originally believed (5).

Studies have shown that prurigo pigmentosa lesions are symmetrically spread on the back, chest, and neck. In our case, the lesions were also observed in these locations, forming a symmetrical pattern. As seen in our case, lesions in the early stage of the disease consisted of erythematous papules and plaque that progressed into papules, papulovesicles, and vesicles and later resolved to leave pigmented macules. It is possible to observe lesions in different stages in the same area (6).

Even though earlier studies claimed that histopathological results were nonspecific, Boer and Ackerman described different histopathological characteristics in three different stages of the disease (7). According to their description, the early stage of the disease is characterized by a neutrophilic infiltration around the vessels in the superficial dermis. Later, the neutrophilic infiltration spreads to the interstitial areas in the papillary dermis. In the following stage, the neutrophils infiltrate the epidermis, causing spongiosis, ballooning, and necrosis in the keratinocytes (7). The biopsy taken from the back of our patient revealed neutrophilic infiltration in the perivascular and interstitial areas of the upper dermis, as well as dyskeratotic cells, clusters of neutrophils, and neutrophilic spongiosis within the epidermis, suggesting that the lesions are in the early stage of the disease. Boer and Ackerman stated that in fully developed lesions of prurigo pigmentosa, lymphocytes and eosinophils appear in the upper dermis, and lead to an infiltration in a patchy, lichenoid pattern (6). This stage is characterized by lymphocytes, as well as spongiosis and ballooning in the epidermis, intra- and subepidermal vesicle formation, and an abundance of necrotic keratinocytes. Lesions in this stage should be differentiated from acute spongiotic dermatitis, viral exanthem, and necrolytic erythemas. The above mentioned authors pointed out that in the later stages of the disease, the epidermis takes a hyperplastic, hyperkeratotic, and hyperpigmented appearance, while the dermis is characterised by lymphocytic infiltration and pigment-laden macrophages (6). During this stage, chronic spongiotic dermatitis and postinflammatory pigmentation should be noted in the differential diagnosis (7).

The etiology of prurigo pigmentosa is not well known but it is believed that the disease may have been caused by some endogenous and exogenous factors. The endogenous factors include ketosis, diet, starvation, diabetes, pregnancy, and Helicobacter pylori infection while exogenous factors include sweating, clothes rubbing against skin' as well as exposure to allergens such as para-amino compounds, trichlorophenol, chrome, and nickel (8-16).

As seen in our case, it is common in women of late adolescent age to lose weight within a short period of time by undertaking carbohydrate-poor diets (16). Because the blood glucose level drops during starvation, a ketogenic metabolism is initiated in the body. The ketone particles that form as a result of this process pass from the blood into tissues and cell cytoplasms, joining metabolic processes within, or remaining around vessels to cause perivascular inflammatory reaction (17).

Various studies discuss the relation between prurigo pigmentosa and starvation, carbohydrate-poor diets due to their high ketogenic effect, and the ketosis observed in diabetes mellitus $(4,8-10)$. In a series of four cases that Hijazi et al. presented in 2014, they observed that one patient developed the lesions after dieting during the month of Ramadan, and two patients developed lesions after a strict diet (7). However, the relation between ketosis and the disease has not been firmly established. Further studies need to be undertaken to understand the pathogenesis of prurigo pigmentosa $(4,7)$.

Prurigo pigmentosa is a rare disease with an unclear etiopathogenesis. The histopathological results vary according to the clinical stages of the disease. The diagnosis may be particularly challenging due to its rare occurrence. Clinicopathological correlation is therefore crucial when diagnosing the disease accurately.

\section{REFERENCES}

1. Nagashima M. Prurigo Pigmentosa. J Dermatol. 1978;5:61-7.

2. Teraki Y, Nishikawa T. Skin diseases described in Japan 2004. J Dtsch Dermatol Ges. 2005;3:9-25.

3. Joyce AP, Horn TD, Anhalt GJ. Prurigo pigmentosa. Report of a case and review of the literature. Arch Dermatol. 1989;125: 1551-4.

4. Kim JK1, Chung WK, Chang SE, Ko JY, Lee JH, Won CH, Lee MW, Choi JH, Moon KC. Prurigo pigmentosa: Clinicopathological study and analysis of 50 cases in Korea. J Dermatol. 2012;39: 891-7.

5. Baykal C, uyukbabani N, Akinturk S, Saglik E. Prurigo pigmentosa: Not an uncommon disease in the Turkish population. Int J Dermatol. 2006;45:1164-68.

6. Boer A, Misago N, Wolter M, Kiryu H, Wang XD, Ackerman AB. Prurigo pigmentosa: A distinctive inflammatory disease of the skin. Am J Dermatopathol. 2003; 25: 117-29.

7. Hijazi M, Kehdy J, Kibbi AG, Ghosn S. Prurigo pigmentosa: A clinicopathologic study of 4 cases from the middle East. Am J Dermatopathol. 2014;36:800-6. 
8. Murao K, Urano Y, Uchida N, Arase S. Prurigo pigmentosa associated with ketosis. Br J Dermatol. 1996;134:379-81.

9. Nakada T, Sueki H, Iijima M. Prurigo pigmentosa (Nagashima) associated with anorexia nervosa. Clin Exp Dermatol. 1998;23: 25-7.

10. Kubota Y, Koga T, Nakayama J. Bullous prurigo pigmentosa and diabetes. Eur J Dermatol. 1998;8:439-41.

11. Park JY, Kim NI. Prurigo pigmentosa associated with pregnancy. Korean J Dermatol. 2000;38:980-2.

12. Erbagci Z. Prurigo pigmentosa in association with Helicobacter pylori infection in a Caucasian Turkish woman. Acta Derm Venereol. 2002;82:302-3.

13. Kim MH, Choi YW, Choi HY, Myung KB. Prurigo pigmentosa from contact allergy to chrome in detergent. Contact Dermatitis. 2001;44:289-92.
14. Atasoy M, Timur H, Arslan R, Ozdemir S, Gursan N, Erdem T. Prurigo pigmentosa in a patient with nickel sensitivity. J Eur Acad Dermatol Venereol. 2009;23:228-30.

15. Lu PH, Hui RC, Yang LC, Yang $\mathrm{CH}$, Chung WH. Prurigo pigmentosa: A clinicopathological study and analysis of associated factors. Int J Dermatol. 2011;50:36-43.

16. Keel PK, Baxter MG, Heatherton TF, Joiner TE Jr. A 20-year longitudinal study of body weight, dieting, and eating disorder symptoms. J Abnorm Psychol. 2007;116:422-32.

17. Meas T, Taboulet P, Sobngwi E, Gautier JF. Is capillary ketone determination useful in clinical practice? In which circumstances? Diabetes Metab. 2005; 31: 299-303. 